\title{
Analysis on Tourists' Preferences for Rural Tourism Destinations in Romania
}

\author{
Andra Porutiuu ${ }^{1}$, Olivia Paula Tirpe ${ }^{2}$ (D), Camelia Oroian ${ }^{1}$, Valentin C. Mihai ${ }^{1} \mathbb{D}$, Gabriela O. Chiciudean ${ }^{1}$, \\ Daniel I. Chiciudean ${ }^{1}$ and Crina Porutiu ${ }^{3, *}$
}

1 Department of Economic Sciences, Faculty of Horticulture, University of Agricultural Sciences and Veterinary Medicine, 400372 Cluj-Napoca, Romania; andra.porutiu@usamvcluj.ro (A.P.);

camelia.oroian@usamvcluj.ro (C.O.); valentin.mihai@usamvcluj.ro (V.C.M.); gabriela.chiciudean@usamvcluj.ro (G.O.C.); daniel.chiciudean@usamvcluj.ro (D.I.C.)

2 Department of Animal Husbandry and Agritourism, Faculty of Environmental Protection, University of Oradea, 26 Gen. Magheru St., 410087 Oradea, Romania; tirpepaula@yahoo.com

3 Department of Marketing, Faculty of Economics and Business Administration, Babeș-Bolyai University, 400084 Cluj-Napoca, Romania

* Correspondence: crina.porutiu@econ.ubbcluj.ro; Tel.: +40-745-057-849

Citation: Poruțiu, A.; Tirpe, O.P.; Oroian, C.; Mihai, V.C.; Chiciudean, G.O.; Chiciudean, D.I.; Poruțiu, C. Analysis on Tourists' Preferences for Rural Tourism Destinations in Romania. Societies 2021, 11, 92. https://doi.org/10.3390/ soc11030092

Academic Editor: Gregor Wolbring

Received: 14 June 2021

Accepted: 30 July 2021

Published: 4 August 2021

Publisher's Note: MDPI stays neutral with regard to jurisdictional claims in published maps and institutional affiliations.

Copyright: (c) 2021 by the authors. Licensee MDPI, Basel, Switzerland. This article is an open access article distributed under the terms and conditions of the Creative Commons Attribution (CC BY) license (https:// creativecommons.org/licenses/by/ $4.0 /)$.

\begin{abstract}
Consumer behavior plays an important role in establishing the marketing strategies of a tourism destination. Analysis of traveling motivation offers valuable information regarding the characteristics and trends of tourism demand. In this context, the aim of this paper is to determine tourists' preferences regarding rural tourism destinations. To achieve the purpose of the paper, a survey was conducted among tourists from rural areas of Cluj County. The data were analyzed using descriptive statistics and statistical tests were applied to determine if there were any significant differences among different groups. The results revealed that the respondents prefer to travel in small groups, especially during summer. They are concerned about the security and safety of the destination, and the price also plays an important role in choosing a tourism destination. Cultural attractions and adventure tourism possibilities are more appreciated by younger respondents. Future research should focus on post-pandemic tourist behavior and new tourist products should be developed to fulfill tourists' expectations.
\end{abstract}

Keywords: tourists' behavior; rural destinations; tourists' expectations

\section{Introduction}

The issue of preferences, as a non-economic determinant for tourism development that can lead to a higher number of tourists and to an increase regarding tourism receipts, was not been frequently tackled in literature on tourism demand until the mid-1990s, as most of the studies had been focusing on tourism's economic determinants. Tourismrelated scientific literature undoubtedly shows that studying tourists' preferences can contribute to tourism development [1]. Consumer behavior in tourism literature plays an important role in determining the extent to which tourism preferences can manifest. First of all, the importance of tourism and travel motivations have been identified as the starting points for pinpointing and studying preferences as variables in tourist behavior. Scientific literature reveals different types of motivations and behaviors, depending on the type of tourism practiced (conventional or rural). For the conventional tourist, the motivations can be socio-psychological (escape from the routine, self-exploration and evaluation, relaxation, prestige, regression, the improvement of family relationships and the facilitation of social relations) and cultural (novelty and education), whereas for rural tourists, motivations can be a variant of the motivations of general tourists and are strictly related to nature, culture and the environment (contact with nature; rest and tranquility; purity of air and water; open spaces and a healthy environment; gastronomy; agricultural activities; discovering another culture; the kindness and hospitality of the local population; 
contact with architectural, ethnographic and material heritage; and the opportunity to "travel to the past" while enjoying the comforts of the present) [2]. As tourists' motivation and behavior can be different depending on the form of tourism practiced, it can be implied that the form of tourism and its perceived attractiveness can be identified as criteria for studying tourist preferences. As some authors show, family and friends' behavior and experiences can be a strong influence in tourist behavior, motivation and satisfaction [3]. The criteria on how tourism is practiced regarding companionship (friends, family and children) can be identified as an issue of interest in the study of consumer preferences in tourism. Studies show that the issue of authenticity in tourist experiences is becoming increasingly important regarding tourist behavior and tourist motivation, with a special focus on existential authenticity which can be an alternative source in tourism, regardless of whether the toured objects are authentic or not. This concept can be looked upon from two different angles: intrapersonal and interpersonal-implying that existential authenticity can contribute to a greater variety of tourist experiences and explain the authenticity-seeking model in tourism [4]. The author suggests there is an ascending tendency for tourism to be regarded as a lifestyle feature that is more effortless and spontaneous, rather than serious, practical or even romantic, enabling people to escape more easily from their daily lives [4]. Thus, the planning or lack of it in travel decision-making is an important issue in studying tourist preferences. One of the goals regarding tourism development should be reaching sustainable tourism as it is defined in the scientific literature: a form of tourism that has the ability to generate external benefits from the environment, contributing to environmental protection and conservation, while ensuring a constant rational and symbiotic relationship with the environment. Sustainable tourism can be developed through sharing experiences, ideas and resources within social systems from the bottom up with the regional scale being recognized as appropriate for the implementation of local participative actions aimed at the sustainable development of destinations [5]. However, in order to build sustainable tourism destinations, it is essential to identify the consumers' preferences when it comes to travelling, accommodation, food, souvenirs and other types of expenditures necessary for a satisfying voyage.

First, what type of elements lure a tourist to choose a rural destination? In contrast to the generic tourism where the tourists' motivations to travel are very broad, rural tourism has become relevant on the tourism market by bringing to the center of interest only one specific attraction that they rely on, such as the landscape, farm life, architecture or environment, therefore the study of the main characteristics of such visitors or tourists was needed [6]. The environment was the main motivational factor for tourists who chose to travel to the rural areas of Serbia, while the possibility for adventure activities was the least desired [7]. Other mentioned motivations included the desire for the feeling of freedom, relaxation, to try something new and different, the interaction with nature and hosts and to gain knowledge of different ways of life, history, culture, etc. The study conducted in Extremadura, Spain, highlighted new motivations for tourists when choosing a rural destination such as authenticity, personalized educational and emotional experiences and direct contact with one's roots [6,8]. Tourists' segmentation represents a very important issue that has been approached by many scholars, since the motivations and preferences differ from one country to another. In the rural areas of Korea, tourism is sought for its "learning" opportunities, "excitement" or "family togetherness", not for the countryside itself [8], and these results are supported by other studies as well [9-11]. The perspective is quite different in Western Europe for example, where the rural destinations are perceived as a source of aesthetically pleasing landscapes and the possibility to admire the natural environment, the fauna and flora [9-11] and most of all for the tranquility [12-15]. It became obvious that the motivations to choose rural tourism are related to the natural or anthropic resources of each country or by the cultural context [16]. In Gambia, Africa, rural tourists seek nature and heritage, experiences and beach attractions [10], while the Spanish tourists are attracted by the outdoor or cultural activities, or simply by the typical rural life [11]. Moreover, rural tourism is perceived as an important factor in revitalizing old and 
disfavored communities, both in the summer and during the most important occasions, such as Christmas or the Holy week [12]. Tourists' preferences must be analyzed from different points of view. Regarding the type of lodging preferred by tourists when they choose to travel to rural destinations, there is a variety of preferences, low price being often an important criterion in the process of choice [13], so chalets, camping sites and small hotels are at the top of tourists' preferences in Lebanon. The same authors stated that summer is the season mostly preferred for rural holidays, most tourists travel in a selforganized manner and the best group size varies between 5 and 10 persons. One-day trips or weekend trips are mostly preferred in terms of duration for a rural destination and the visit pattern relies on friends and family [13]. In China, a long-stay vacation in a rural area is considered to be an important element of revitalizing the rural economy, but for a longer voyage, there are some issues that must be taken into consideration at the destination: comfort, the rurality itself, publicity and familiarity [14]. What is more surprising is the fact that rural tourism facilities gain different attributes for urban consumers who more appreciate the natural simplicity of these facilities than wanting luxury and elegance [15].

In Romania, rural tourism is still a relatively new tourism product for the residents, who often prefer the mountains or the sea when it comes to holiday compared to only $2 \%$ who declared that they would prefer a rural tourism destination [17]. Many scholars consider that the potential for a sustainable development is very high [18-22] Rural tourism and agrotourism has developed rapidly in the last few decades in Romania [19]. Studies conducted in Romania stated that the most sought form of accommodation in the rural areas is represented by the agrotourism boarding houses, both by foreign tourists and Romanian tourists [20]. Rural tourism is considered to have reached an increased growth phase from the point of view of the demand but also from the perspective of the increasing number of rural accommodation facilities [21], even if the level of tourist satisfaction does not always follow this high [22]. Analysis of rural tourists' behavior offers important information for developing sustainable tourism products.

In this context, the current paper analyses the tourists' preferences for choosing a rural destination and the following questions arise: What is the tourist profile within rural destinations? What are the main factors of attractiveness for spending a holiday in rural areas? What types of services do tourists from rural areas prefer?

\section{Materials and Methods}

\subsection{Study Area}

Cluj County is located in the North-West Development Region of Romania and has a high potential for all types of tourism, including rural tourism. The mountain area covers an important part of the territory $\left(6650 \mathrm{~km}^{2}\right)[23,24]$, underlined by the high anthropic tourism heritage potential. Within this region, the rural areas exhibit an important ecumenic tourism supply, mainly because of the variety of religious buildings (wooden churches, fortified churches, monasteries, etc.) and the high number of religious buildings (more than 220 religious buildings exist within the rural-mountain area of Cluj County).

Cluj County exhibits a high tourist potential, reflected in the existence of a wide range of leisure activities offered (hiking, mountaineering, summer and winter sports, children and youth camps, spa treatment, etc.) and in the development of all areas of modern technology [24].

The areas and objectives of great tourist attractiveness must be mentioned: Salina Turda, modern leisure and treatment destination; Băişorii Mountain, a resort favorable for winter sports; the Trascăului Mountains, especially spectacular due to the landscape forms, imposing rocks and caves; Băişoara, an area that stands out through landscapes of exceptional beauty, sought after in summer by hiking enthusiasts and in winter by those who practice "white sports"; the Gilău area-Lake Tarniţa, which offers special conditions for leisure during weekends; and the Lake Beliş-Fântânele area, sought for the superb landscape provided by the lake and the surrounding mountains [25]. 
As can be observed in Table 1, the number of accommodation units increased more than twofold during the last five years, from 84 in 2016 to 192 in 2020, while the capacity in function decreased. The decrease of the capacity in function during 2020, compared to the other four analyzed periods, can be explained by the reduction of the tourism season, mainly due to the COVID-19 pandemic restrictions. The restrictions related to the mobility of persons, the number of tourists accepted within accommodation units and affected the arrivals and overnight stays recorded in 2020. It was observed that the average length of stay was approximately 2 nights, indicating that the rural area of Cluj County is more a weekend destination. The occupancy rate was approximately $22 \%$ during the analyzed period, exceptions being the years 2017 (24.16\%) and 2020 (15.43\%).

Table 1. Time evolution of tourism indicators in rural areas of Cluj County.

\begin{tabular}{cccccc}
\hline Tourism Indicators/Year & $\mathbf{2 0 1 6}$ & $\mathbf{2 0 1 7}$ & $\mathbf{2 0 1 8}$ & $\mathbf{2 0 1 9}$ & $\mathbf{2 0 2 0}$ \\
\hline Accommodation units (no.) & 84 & 147 & 170 & 188 & 192 \\
Accommodation capacity in functions (bed-places) & 710,573 & 899,257 & 995,002 & $1,004,468$ & 673,065 \\
Arrivals (no. of tourists) & 80,604 & 110,628 & 116,823 & 118,376 & 55,393 \\
Overnights (no.) & 155,738 & 217,272 & 226,323 & 226,412 & 103,843 \\
Average length of stay (no. of nights) * & 1.93 & 1.96 & 1.94 & 1.91 & 1.87 \\
Occupancy rate (\%) & 21.92 & 24.16 & 22.75 & 22.54 & 15.43 \\
\hline
\end{tabular}

* Own calculation based on the official data from the National Institute of Statistics Romania [26].

\subsection{Research Methodology}

Firstly, previous research regarding tourists' preferences were analyzed. For this, Google Scholar and Web of Science databases were explored, using "tourists' preferences" and "rural tourism preferences" as the main key words. Motivational factors that influence the choice of a rural tourism destination were identified and analyzed in order to develop the research instrument. Motivational factors affecting tourists' decision making for visiting a rural destination include the feeling of freedom, relaxation, the desire to try something new and different, the interaction with nature and hosts, the gaining of knowledge of different ways of life, history, culture, educational and emotional experiences and adventure experiences [6-8].

The research method used to collect the primary data was the survey based on a questionnaire. Questionnaires represent a valuable research instrument for acquiring information on tourists' perceptions and have been used in several previous studies $[4-12,16,27,28]$.

The questionnaire consisted of ten closed/open-ended questions. A filter question was used in order to identify the respondents that were practicing rural tourism in the research area. The questionnaire consisted of three main parts: The first part contained information regarding the socio-demographic characteristics of the respondents (gender, age, type of residency, professional status and number of children in the family). The second part contained questions regarding the travel habits of the respondents (group size and structure, type of accommodation and preferred season for visiting the rural area). The third part of the questionnaire grouped 11 items in order to determine the attractiveness of the rural destinations. Each item was evaluated on the Likert scale from 1 to 5, where 1 means not important at all and 5 means very important.

A convenience sampling method was used. A total number of 212 questionnaires were collected with 174 being validated in the end. The survey was conducted online on 3 different travel groups from social media (Facebook) during March 2020. The selected groups were those addressed to travelers in rural areas of Romania.

As can be observed, the majority of respondents were female $(67.8 \%)$, while $32.2 \%$ of the respondents are male. Regarding the residency of the respondents, it was noted that the majority of the respondents were from rural areas (51.7\%) and aged between 18-30 years old in $79.4 \%$ of the cases. Regarding professional status, $36.8 \%$ declared that they were students, while $55.5 \%$ were employees (Table 2). 
Table 2. Socio-demographic characteristics of respondents.

\begin{tabular}{cccc}
\hline Characteristic & Category & $\boldsymbol{n}$ & $\%$ \\
\hline \multirow{3}{*}{ Gender } & Female & 118 & 67.8 \\
& Male & 56 & 32.2 \\
\hline \multirow{2}{*}{ Age } & $18-30$ years old & 138 & 79.4 \\
& $30-42$ years old & 18 & 10.3 \\
& $42-54$ years old & 18 & 10.3 \\
\hline \multirow{2}{*}{ Residency } & Urban & 84 & 48.35 \\
& Rural & 90 & 51.7 \\
\hline \multirow{2}{*}{ Socio-professional status } & Student & 64 & 36.8 \\
& Employee & 96 & 55.2 \\
& Entrepreneur & 10 & 5.7 \\
& Unemployed & 4 & 2.3 \\
\hline \multirow{2}{*}{ Children in the family } & Yes & 46 & 26.6 \\
& No & 128 & 73.4 \\
\hline
\end{tabular}

The collected data were analyzed using descriptive statistics and interferential statistics. The chi-square test was used to determine if there were any differences between the group traveling with children and the one traveling without children and the type of accommodation chosen. The Mann-Whitney U test and the Kruskal-Wallis test were used to analyze whether there were any significant differences regarding the perceptions of the attractiveness factors for rural destinations based on the socio-demographic characteristics. Data were analyzed using SPSS Statistics for Windows, Version 23.0.

\section{Results}

\subsection{Traveling Behavior}

In order to identify the traveling habits of tourists in rural areas, information was collected relating to the size of the group, period of the year, type of accommodation and access services.

The results showed that in general the tourists prefer to travel in small groups of $2-5$ persons $(66.3 \%)$ during their visits in rural areas (Figure $1 \mathrm{a})$. In $88.5 \%$ of the cases, they declared that they prefer to travel with friends, while $57.5 \%$ mentioned that family members were also part of the travel group to rural areas (Figure 1b).

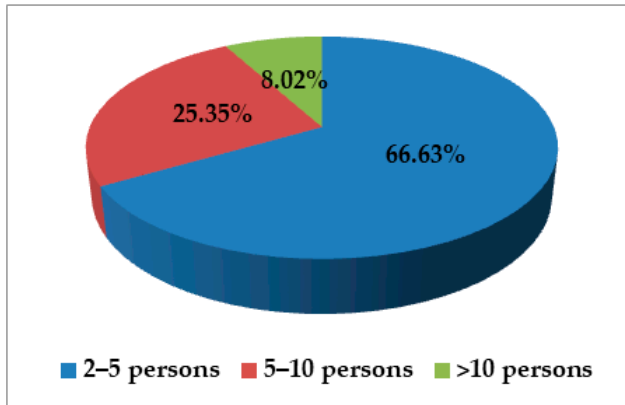

(a)

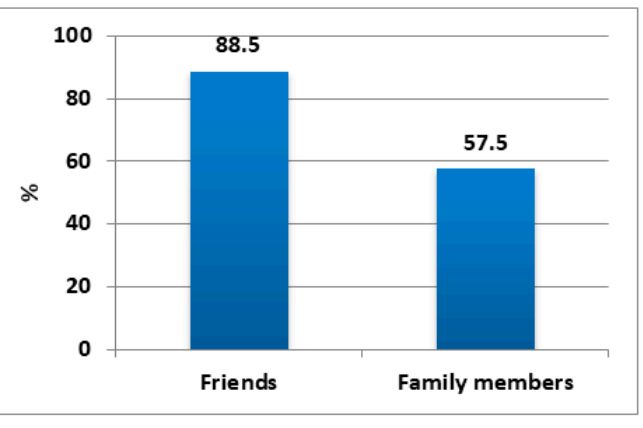

(b)

Figure 1. (a) Preferred tourist group size; and (b) percentage of friend and family tourist group members.

The main season preferred by tourists to visit rural destinations from Cluj County is summer (92.8\%) (Figure 2). On being asked when they prefer to visit the rural destinations, on weekends or during the holidays, it was noticed that $48.3 \%$ of tourists visit rural destinations over weekends, while $52.7 \%$ declared that they prefer to visit rural destinations during the holidays. This could be an explanation of why the main season for visiting rural 
destinations is the summer; summertime is when students have their break, which allows them to travel more.

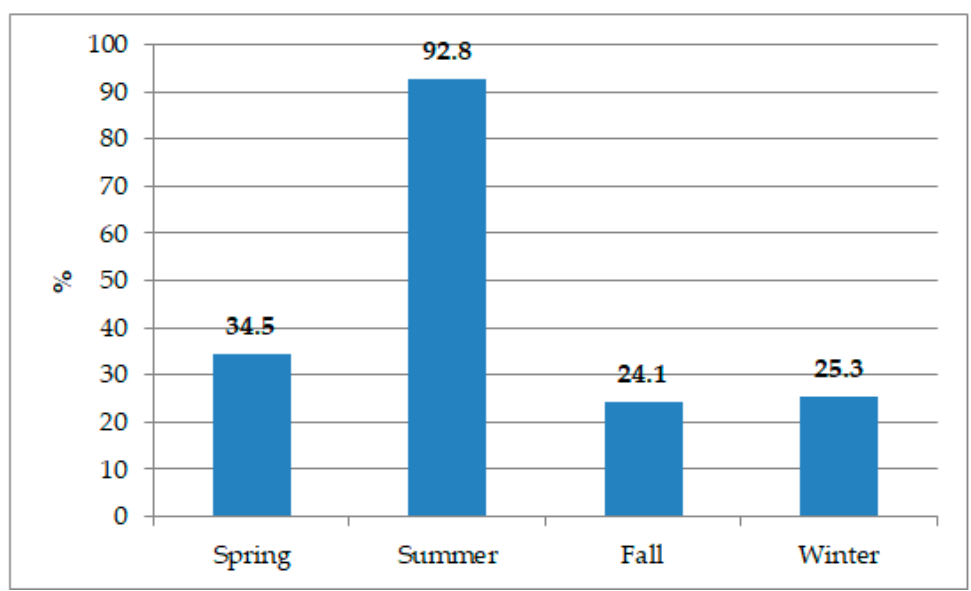

Figure 2. Distribution by visiting season.

The main type of accommodation mentioned by the tourists was the chalet (66.7\%). This indicates that tourists in general prefer a less organized form of tourism and are actively involved in arranging the daily program (eating, entertainment etc.). At the same time, an important segment of the respondents (more than 35\%) declared that they used to stay in their second residency during their visit to rural destinations (Figure 3).

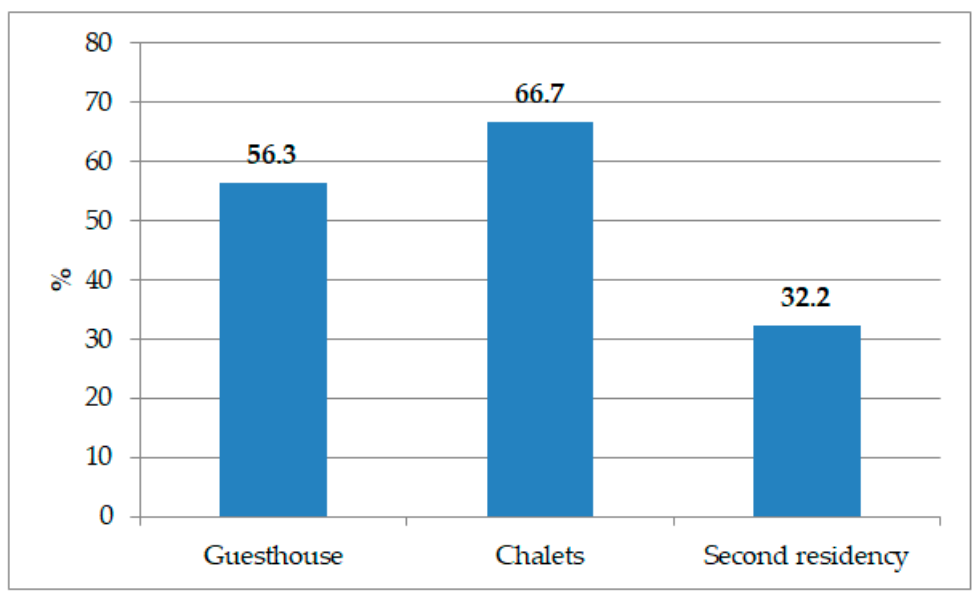

Figure 3. Type of accommodation used during the visit to rural destinations.

It was also noticed that the percentage of those that booked a room in a guesthouse was higher in the case of tourists travelling with children compared to those travelling without children $(55.5 \%)$. Chalets are more often preferred by those that do not have children in their traveling group (68\%). An explanation for this situation could be the fact that families travelling with children in general prefer a more organized form of tourism. Furthermore, using the chi-square test, an analysis was conducted in order to see if there were any differences when choosing the accommodation unit between the group travelling with children and the one travelling without children. The results show that there are no differences between the two groups $(p>0.05)$ (Table 3$)$.

\subsection{Analysis of the Attractiveness of the Rural Destination}

Subsequently, the attractiveness of the rural destinations was analyzed. For this purpose, the respondents had to evaluate the importance of different types of tourist 
resources on a Likert scale from 1 to 5 , where 1 means not important at all and 5 means very important.

Table 3. Analysis of accommodation type used based on type of tourist group.

\begin{tabular}{ccc}
\hline Type of Accommodation & Travelling with Children & Travelling without Children \\
\hline Guesthouse & $60 \%$ & $55.5 \%$ \\
\hline Chalets & $p$-value $=0.752$ & \\
\hline & $60 \%$ & $68 \%$ \\
\hline Second residency & $p$-value $=0.547$ & $31.9 \%$ \\
\hline & $33.3 \%$ & \\
\hline
\end{tabular}

The analysis exhibits that the diversity of entertainment options (ST1) within a touristic destination was evaluated by almost half of the respondents as being very important (mean $>4$ ) (Table 4). The importance of diversity of entertainment options was also highly appreciated by those travelling without children (4.28), compared to the group that was travelling with children (3.73) $(p<0.05)$. This result was also supported by the fact that there are correlations between this characteristic and tourism adventure facilities (ST4) and cultural attractions (ST6, $p<0.05)$. Groups that were travelling with children were more preoccupied with the variety of services (4.60) and the security and safety of the destination (4.80), but there were no significant statistical differences between these two groups (Table 5).

Table 4. Importance of attraction factors.

\begin{tabular}{|c|c|c|c|c|c|c|c|}
\hline \multirow{2}{*}{ Statement } & \multicolumn{5}{|c|}{ Scale $(\%)$} & \multirow{2}{*}{ Mean } & \multirow{2}{*}{ SD } \\
\hline & 1 & 2 & 3 & 4 & 5 & & \\
\hline Diversity of entertainment options (ST1) & 1.1 & 1.1 & 24.1 & 25.3 & 48.3 & 4.18 & 0.922 \\
\hline Farm tours options (ST2) & 8.0 & 19.5 & 26.4 & 21.8 & 24.1 & 3.34 & 1.265 \\
\hline Ecotourism facilities (ST3) & 6.9 & 13.8 & 35.6 & 21.8 & 21.8 & 3.38 & 1.174 \\
\hline Tourism adventure facilities (ST4) & 6.9 & 8.0 & 13.8 & 27.6 & 43.7 & 3.93 & 1.237 \\
\hline Hiking trails (ST5) & 5.7 & 11.5 & 19.5 & 18.4 & 44.8 & 3.85 & 1.272 \\
\hline Cultural attractions (ST6) & 8.0 & 8.0 & 25.3 & 25.3 & 33.3 & 3.68 & 1.224 \\
\hline Religious attractions (ST7) & 29.9 & 23.0 & 27.6 & 5.7 & 13.8 & 2.51 & 1.121 \\
\hline Price of accommodation (ST8) & 1.1 & 0 & 28.7 & 31.0 & 39.1 & 4.08 & 0.852 \\
\hline Variety of services (ST9) & 0.0 & 0.0 & 14.9 & 31.1 & 54.0 & 4.39 & 0.737 \\
\hline Security and safety (ST10) & 0 & 0 & 3.4 & 23.0 & 73.6 & 4.70 & 0.531 \\
\hline Distance from home (ST11) & 1.1 & 5.7 & 28.7 & 29.9 & 34.5 & 3.91 & 0.984 \\
\hline
\end{tabular}

High importance scores were attributed to the price for accommodation (mean $>4$ ). This could also explain why, regardless of travelling with or without children, the respondents preferred chalets (minimal services meaning low prices).

For $73.6 \%$ of the respondents, the safety and security of the destination was very important (mean $>4$ ). This aspect could be explained by the fact that the research was conducted at the beginning of lockdown, due to the COVID-19 pandemic, in which safety and security was a real concern.

The analysis shows that tourism adventure facilities (ST4) is statistically significant among the age groups $(p<0.05)$, as adventure facilities address younger people.

The residency characteristic also exhibits statistical significance regarding farm tours options (ST2) and religious attractions (ST7), showing that the attractiveness of a highly rural aspect of a destination differs from urban to rural residents. Also, more than a quarter of the respondents (29.9\%) consider religious attractions (ST4) not important at all regarding the attractiveness of a rural destination. 
Table 5. Results of the Mann-Whitney U test and the Kruskal-Wallis test of socio-demographic characteristics and attraction factors.

\begin{tabular}{|c|c|c|c|c|c|c|c|c|c|c|c|c|}
\hline Characteristic & Category & ST1 & ST2 & ST3 & ST4 & ST5 & ST6 & ST7 & ST8 & ST9 & ST10 & ST11 \\
\hline \multirow{3}{*}{ Gender } & Female & 4.29 & 3.42 & 3.53 & 3.95 & 3.83 & 3.81 & 2.66 & 4.17 & 4.47 & 4.75 & 3.92 \\
\hline & Male & 3.96 & 3.18 & 3.07 & 3.89 & 3.89 & 3.39 & 2.18 & 3.89 & 4.21 & 4.61 & 3.89 \\
\hline & $p$-value & 0.137 & 0.407 & 0.098 & 0.480 & 0.851 & 0.234 & 0.087 & 0.188 & 0.233 & 0.098 & 0.947 \\
\hline \multirow{4}{*}{ Age } & 18-30 years & 4.20 & 3.32 & 3.41 & 4.12 & 3.77 & 3.77 & 2.54 & 4.03 & 4.35 & 4.68 & 3.87 \\
\hline & 30-42 years & 4.44 & 3.56 & 3.56 & 3.56 & 4.11 & 3.44 & 2.22 & 4.44 & 4.56 & 4.78 & 4.11 \\
\hline & 42-54 years & 3.78 & 3.33 & 3.00 & 2.89 & 4.22 & 3.22 & 2.56 & 4.11 & 4.56 & 4.78 & 4.00 \\
\hline & $p$-value & 0.415 & 0.826 & 0.728 & $0.018^{*}$ & 0.284 & 0.596 & 0.786 & 0.350 & 0.521 & 0.596 & 0.667 \\
\hline \multirow{2}{*}{ Residency } & Rural & 4.13 & 3.67 & 3.47 & 3.82 & 3.98 & 3.62 & 2.82 & 3.93 & 4.47 & 4.69 & 3.93 \\
\hline & $p$-value & 0.598 & $0.009 * *$ & 0.529 & 0.556 & 0.379 & 0.926 & 0.025 * & 0.109 & 0.216 & 0.816 & 0.894 \\
\hline \multirow{5}{*}{ Socio-professional status } & Student & 4.19 & 3.31 & 3.46 & 4.02 & 3.71 & 3.67 & 2.58 & 4.13 & 4.27 & 4.65 & 3.75 \\
\hline & Employee & 4.19 & 3.25 & 3.19 & 3.91 & 4.00 & 3.81 & 2.44 & 4.03 & 4.56 & 4.72 & 4.09 \\
\hline & Entrepreneur & 4.20 & 4.00 & 3.60 & 3.20 & 4.20 & 2.80 & 1.60 & 4.20 & 4.40 & 5.00 & 4.40 \\
\hline & Unemployed & 4.00 & 4.00 & 4.00 & 4.00 & 4.00 & 4.00 & 4.00 & 3.50 & 4.50 & 5.00 & 3.50 \\
\hline & $p$-value & 0.994 & 0.565 & 0.759 & 0.806 & 0.435 & 0.507 & 0.190 & 0.740 & 0.366 & 0.382 & 0.169 \\
\hline \multirow{2}{*}{ Travelling with children } & Yes & 3.73 & 3.27 & 2.87 & 2.87 & 3.67 & 2.93 & 2.67 & 3.93 & 4.60 & 4.80 & 4.13 \\
\hline & $p$-value & $0.045^{*}$ & 0.845 & 0.115 & $0.001 * *$ & 0.440 & $0.028^{*}$ & 0.427 & 0.481 & 0.235 & 0.496 & 0.386 \\
\hline
\end{tabular}




\section{Discussion}

Tourism can contribute to the development of various social and economic activities. It can also be used to evaluate the quality of the environment. Tourism and territorial development are linked. Both are related to the development of rural areas, which are ideal for attracting tourists due to their unique characteristics. Through the awareness of various local stakeholders, the development of tourism can be achieved. Rural tourism is a type of small-scale business that is managed by local people with strong ties to the community. The main factor that influences a person's desire to travel is the availability of instant and authentic tourism information. A good tourism program can help people get the most realistic and instant information about the various tourist destinations. It can also help boost the local economy by attracting visitors and developing tourism industries [29].

Traveling behavior in rural destinations is influenced by several factors such as the size of the travel group, the travel season, the type of accommodation and other additional services. The results indicated that Romanian tourists prefer to travel in small groups of $2-5$ persons when they choose to visit rural areas, while a study from Lebanon stated that larger travel groups of 5-10 persons are mostly preferred by the respondents [13]. An explanation for this fact could rely on the specific culture of each country, as in Lebanon, traditional, large and extended families are still dominant and travel together [30], while in Romania, part of the respondents declared that they prefer to travel with friends, even if for some respondents their family members are part of the group.

Rural destinations are preferred by tourists that mostly travel in small groups of family members and friends during the summer season. Traditional accommodation facilities such as chalets are the preferred type of accommodation in rural destinations, as the price is lower due to the minimal services provided. The attractiveness of a rural destination is determined by several factors that influence the willingness to travel to rural destinations. When it comes to choosing the season for travelling, the Romanian tourists almost unanimously agreed that the summer season is the most appropriate time of the year for travelling to rural destinations - a fact that aligns with previous research [13]. The summer season is also the holiday season and a large part of the respondents declared that they travel during their free time, but the sunny weather is likely another factor that explains their preference for summer.

With regards to the main type of accommodation, more than half of the Romanian respondents mentioned the chalet: a fact that could be explained by the relatively cheap price and the preference for a less organized vacation. Tourists from other countries also mentioned the chalet as a preferred accommodation unit [13,31], while previous studies from Romania mentioned agrotourism boarding houses as being preferred both by foreign and Romanian tourists [20,32]. Given the fact that these studies were conducted seven and fourteen years ago, it can be observed that tourist preferences change over time. It was observed that families with no children preferred the chalet, the motivation for which could rely on the reduced facilities or be related to having a less organized voyage which is particular to this type of accommodation. In the Czech Republic, the chalet is preferred by traditional tourists aged between 40 and 49 years old, so there are similarities between the two cases [31].

An important aspect that must be deeply analyzed concerns the importance of the attraction factors for Romanian tourists. The respondents mentioned the "security and safety" factor as the most important factor when they choose a rural destination, but previous studied did not mention it, mainly because of the specific context in which this research was conducted-during the pandemic when tourists were especially concerned about these aspects. The second most important factor for the Romanian respondents was the "variety of services" offered by the rural areas. What is very striking is the fact that the Romanian tourists were focused on the tourism services and not on the traditional attractions within a rural destination, like the previous studies from different countries mentioned: the landscape, farm life, architecture or the environment $[6-8,16,27]$. 
The "diversity of entertainment options" was the third most important factor in the process of choice of a rural destination and fourth was the "price for accommodation", which was related to the most preferred type of accommodation, the chalet.

On the other hand, some studies exhibit that income, distance and the residential style of house do not influence the choice of rural accommodation, while age, company, education, rural residential experience, expenditure, marital status, gender, occupation and consumer loyalty are variables that explain significant differences among individuals when choosing the type of accommodation at a rural destination [33]. To this extent, cultural activity as a form of tourism has begun to increase since the 1980s as cultural and natural heritage tourism, being "the most rapidly growing international sector of the tourism industry" [34].

Studies show that tourists better appreciate the opportunity to be engaged in physical activities and to explore the natural environment through hiking and other kinds of activities related to adventure tourism [22]. Some of the most highly valued features regarding the attractiveness of rural destinations are the diversity of entertainment options and safety and security features. Diverse entertainment facilities, adventure facilities and cultural attractions are considered to be important aspects for all tourists, especially for the ones travelling without children.

This research highlights the preferences of tourists regarding rural tourism destinations in Romania in order to achieve an enhancement of tourism attractiveness. This could also represent a starting point for rural tourism destinations to improve their image, promotion and marketing strategy, which could lead to an improvement of the country's rural strategy development in order to improve regional economic development.

Further research regarding the concern for safety and security when travelling may reveal different results in the post-pandemic period, as tourists might not have such high concerns regarding safety when the global crisis is over. Future research should consider rural tourism strategy and management, try to mix these aspects with rural tourists' preferences and exhibit any opportunities to develop tourism in order to support rural communities. Focusing on tourists' preferences and emotional aspects of rural tourism can improve understanding regarding tourist expectations and support the development of more attractive rural tourism experiences, which can contribute to the success of rural tourism companies.

The authors consider Romania to not be a particular market, regarding tourists' preferences, for rural tourist destinations, as other research exhibits mostly the same results on this matter, so the results obtained could be extrapolated to other countries and regions in Romania in order to provide a good base for understanding tourist expectations and supporting the development of more attractive rural tourism experiences and better rural tourism destinations.

As the pandemic comes to a close and restrictions lifted, rural tourism destination promoters should focus on providing relevant information regarding aspects that tourists consider important nowadays, in order to make their destinations more attractive to a wider range of potential tourists.

Author Contributions: Conceptualization, A.P. and C.O.; Formal analysis, G.O.C.; Methodology, O.P.T., V.C.M. and C.P.; Validation, V.C.M. and D.I.C.; Visualization, O.P.T.; Writing-original draft, A.P. and G.O.C.; Writing—review \& editing, A.P., C.O., G.O.C. and C.P. All authors have read and agreed to the published version of the manuscript.

Funding: This research received no external funding.

Institutional Review Board Statement: Ethical review and approval were waived for this study due to the fact that participation was voluntary and all data were anonymous.

Informed Consent Statement: Informed consent was obtained from all participants in the study.

Data Availability Statement: Not applicable.

Conflicts of Interest: The authors declare no conflict of interest. 


\section{References}

1. Lu, Z.; Li, H.; Lau, C.K.M.; Isah, A.B. Preferences and Tourism Development under Uncertainty: An Empirical Study. Sustainability 2021, 13, 2534. [CrossRef]

2. López-Sanz, J.M.; Penelas-Leguía, A.; Gutiérrez-Rodríguez, P.; Cuesta-Valiño, P. Sustainable Development and Consumer Behavior in Rural Tourism-The Importance of Image and Loyalty for Host Communities. Sustainability 2021, 13, 4763. [CrossRef]

3. Teng, Y.; Ma, Z.; Jing, L. Explore the World Responsibly: The Antecedents of Ethical Tourism Behaviors in China. Sustainability 2021, 13, 4907. [CrossRef]

4. Wang, N. Rethinking authenticity in tourism experience. Ann. Tour. Res. 1999, 26, 349-370. [CrossRef]

5. Díaz-Pérez, F.M.; García-González, C.G.; Fyall, A. Accommodation, Seasonality and Domestic Tourism to National Parks: Implications for Environmental Policy. Sustainability 2021, 13, 5072. [CrossRef]

6. Leco, F.; Hernández, J.M.; Campón, A.M. Rural Tourists and Their Attitudes and Motivations Towards the Practice of Environmental Activities such as Agrotourism. Int. J. Environ. Res. 2013, 7, 255-264.

7. Demirović, D.; Berjan, S.; Milentijević, N.; El Bilali, H.; Syromiatnikova, Y. Exploration of tourist motivation and preferred activities in rural areas. J. Geogr. Inst. Jovan Cvijic SASA 2019, 69, 29-37. [CrossRef]

8. Park, D.-B.; Yoon, Y.-S. Segmentation by motivation in rural tourism: A Korean case study. Tour. Manag. 2009, 30, 99-108. [CrossRef]

9. Song, D.Y. Why do people visit the countryside? Push \& pull factors. J. Green Tour. 2005, 12, 117-144.

10. Rid, W.; Ezeuduji, I.O.; Pröbstl-Haider, U. Segmentation by motivation for rural tourism activities in The Gambia. Tour. Manag. 2014, 40, 102-116.

11. Molera, L.; Pilar Albaladejo, I. Profiling segments of tourists in rural areas of South-Eastern Spain. Tour. Manag. 2007, 28 , 757-767. [CrossRef]

12. Yagüe Perales, R.M. Rural tourism in Spain. Ann. Tour. Res. 2002, 29, 1101-1110. [CrossRef]

13. Ghadban, S.; Shames, M.; Abou Arrage, J.; Abou Fayyad, A. Rural tourism in Lebanon: What does the market reveal? Manag. Avenir 2017, 6, 165-185. [CrossRef]

14. Lyu, J.; Huang, H.; Mao, Z. Middle-aged and older adults' preferences for long-stay tourism in rural China. J. Destin. Mark. Manag. 2021, 19, 100552.

15. Cong, L.; Zhang, Y.; Su, C.H.J.; Chen, M.H.; Wang, J. Understanding Tourists' Willingness-to-Pay for Rural Landscape Improvement and Preference Heterogeneity. Sustainability 2019, 11, 7001. [CrossRef]

16. Dong, E.; Wang, Y.; Morais, D.; Brooks, D. Segmenting the rural tourism market The case of Potter County, Pennsylvania, USA. J. Vacat. Mark. 2013, 19, 181-193. [CrossRef]

17. Avram, D. Trends of tourist demand in Romania. Positioning of the rural tourism among the tourists. Cactus Tour. J. 2017, 15, $14-25$.

18. Bran, D.; Hincu, F.; Ioan, I. Potential of rural tourism in Romania. J. Tour. 2010, 10, $28-31$.

19. Tenie, B.V.-T.; Fintineru, G. What attracts tourists in rural areas? An analysis of the key attributes of agritourist destinations that may influence their choice. AgroLife Sci. J. 2020, 9, 324-333.

20. Vlad, I.M.; Stoian, E. Accomodation preferences of foreign tourists in Romania. Sci. Pap. Ser. Manag. Econ. Eng. Agric. Rural Dev. 2014, 14, 399-404.

21. Pop, C.; Coros, M.; Balint, C. Romanian Rural Tourism: A Survey of Accommodation Facilities. Stud. UBB Negot 2017, 62, 71-126. [CrossRef]

22. Dumitras, D.E.; Mihai, V.C.; Jitea, I.M.; Donici, D.; Muresan, I.C. Adventure Tourism: Insight from Experienced Visitors of Romanian National and Natural Parks. J. Soc. 2021, 11, 41. [CrossRef]

23. Buta, I.; Idu, P.D.; Edroiu, N. Ghid Turistic al Judeţului Cluj; Sport-Turism Publishing House: Bucharest, Romania, 1980.

24. Racasan, B.; Marian-Potra, A.C.; Gaman, G. Tourism potential value assessment model for rural-mountain and boundary contact areas. Case study: Cluj County, the district of Ciceu and the balneal area of Bacău County (Romania). J. Environ. Tour. Anal. 2016, 4, 74-96.

25. Available online: http:/ / www.cniptcluj.ro/ (accessed on 11 June 2020).

26. Statistics INSSE. Available online: http:/ / statistici.insse.ro:8077/tempo-online/\#/pages/tables/insse-table (accessed on 13 June 2021).

27. Carneiro, M.J.; Lima, J.; Silva, A.L. Landscape and the rural tourism experience: Identifying key elements, addressing potential, and implications for the future. J. Sustain. Tour. 2015, 23, 1217-1235. [CrossRef]

28. Hewlett, D.; Harding, L.; Munro, T.; Terradillos, A.; Wilkinson, K. Broadly engaging with tranquillity in protected landscapes: A matter of perspective identified in GIS. Landsc. Urban Plan. 2017, 158, 185-201. [CrossRef]

29. Zheng, M.-Y.; Chen, C.-C.; Lin, H.-H.; Tseng, C.-H.; Hsu, C.-H. Research on the Impact of Popular Tourism Program Involvement on Rural Tourism Image, Familiarity, Motivation and Willingness. Sustainability 2021, 13, 4906. [CrossRef]

30. Abyad, A. Health care for older persons: A country profile-Lebanon. J. Am. Geriatr. Soc. 2001, 49, 1366-1370. [CrossRef] [PubMed]

31. Jindrová, A.; Dömeová, L. Segmentation of rural tourists in the Czech Republic. Acta Univ. Agric. Silvic. Mendel. Brun. 2011, 59, 117-122. [CrossRef] 
32. Arion, F.; Muresan, I. Analyze of tourists' preferences on rural tourism accomodation facilities in Romania. Bull. USAMV-CN 2007, 64, 309-314. [CrossRef]

33. Park, D.-B.; Yoon, Y.-S.; Lee, M.-S. Determinants of Consumer Preference by type of Accommodation: Two Step Cluster Analysis. J. Glob. Sch. Mark. Sci. 2007, 17, 1-19.

34. Brida, J.G.; Meleddu, M.; Pulina, M. Factors influencing the intention to revisit a cultural attraction: The case study of the Museum of Modern and Contemporary Art in Rovereto. J. Cult. Herit. 2012, 13, 167-174. [CrossRef] 